J. Dairy Sci. 97:7305-7305

http://dx.doi.org/10.3168/jds.2014-97-11-7305

(C) American Dairy Science Association ${ }^{\circledR}, 2014$.

\title{
Erratum to "Efficacy of in vitro embryo transfer in lactating dairy cows using fresh or vitrified embryos produced in a novel embryo culture medium" (J. Dairy Sci. 93:5234-5242)
}

\section{J. Block, L. Bonilla, and P. J. Hansen}

The description of the recipe for modified synthetic oviductal fluid (page 5235) omitted one ingredient. In addition to those ingredients listed in the paper, the medium also contained $1 \mathrm{mg} / \mathrm{mL}$ polyvinyl alcohol.

The authors regret the omission.

\section{REFERENCES}

Block, J., L. Bonilla, and P. J. Hansen. 2010. Efficacy of in vitro embryo transfer in lactating dairy cows using fresh or vitrified embryos produced in a novel embryo culture medium. J. Dairy Sci. 93(11):5234-5242. 